\title{
Legal Values as Organisational Values
}

\author{
Angelo Roberto Gaglioti, (PhD, MA, MSc, LD)
}

Decisions LAB, University Mediterranea of Reggio Calabria, Di.Gi.Ec., Italy

URL:http://dx.doi.org/10.19044/elp.v5no4a1

\begin{abstract}
This paper depicts the basics of a mathematical model of axiological legal analysis, already proposed in several scientific contributions, to explain the nature of legal values, as being characterized by an organizational essence. They are generated in the legal system by the orderly positioning of legal mass (conceptual mass and gap-mass) within legal structures framing paths of claims, acknowledgments, entitlements, and adjudications between (at least) two subjects, referring their interests to the elements of the (legal) world. Once legal mass is positioned in (logically and chronologically) organized legal structures (legal organisms), each unit of mass gain momentum, being attracted by the subjective terminal points of the structure, hence assuming axiological motion, in the two dimensions of axiological Strength and Height. Due to the viewpoint of the observer, within each legal structure gap-mass emerges: this is of units of mass that do not deliver conceptual information, but just chronological information. Two elementary exponential equations describe the slopes of axiological Strength and Height, allowing to weigh the amount of legal value associated to each unit of mass, and consequently to any legal structure (positions, situations, rules and principles). Once a legal conflict occurs, such reasoning permits to solve the dispute in a fairly transparent and objective way, though maintaining a certain area of discretionary power for any decision-maker. Coase theorem of indifference to the status quo ante of the property right does not apply, due to the impact of gap-mass (which implies transaction costs).
\end{abstract}

Keywords: Law, value, mathematics, mass, organization.

\section{Introduction}

The Author has proposed a mathematical model for the axiological analysis of the legal system in previous several scientific contributions (see for ex. Ferrara-Gaglioti, 2012). The aim of the model is that of enabling the solution of legal conflicts in a fairly objective and transparent manner, though preserving a certain area of discretionary power to the decision-maker. 
Making reference to the previous publication on this model for a more detailed explanation of all its core elements (see Gaglioti, 2017), in order to make this paper easily accessible, it will be organized as follows: firstly a basic introduction to the model will be drawn, according to the main factors already introduced in previous academic contributions (see, e plurimis, FerraraGaglioti, 2012); secondly it will be dealt with the issue of the truly nature of legal values, which seem to the Author as being characterized by an organizational essence (both logical and chronological organization: $\lambda$ ójo $\varsigma$

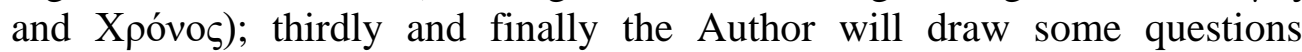
concerning this model, which still need to be thoroughly addressed, currently being open and unsolved. The Author hopes that the feedback of the academic community might lead to the critics and/or to the validation of the proposed model.

\section{Basic Assumptions for this Model:}

The Author adheres to the way of thinking law as a system of values ( $\alpha \xi(0 \varsigma)$ ): so called generic axiologism. Values characterize a reality outlining what is relevant (or irrelevant), what is positive (or negative), what is more (or less) intense (Falzea, 1985).

As to the truly nature of legal values (so called specific axiologism), in the history of legal thought several answers have being given: ideal or real; substantial or formal; subjective or objective (Falzea, 1985).

There are some (mostly) uncontroversial features of law, as a phenomenon: humanity; sociality; normativity (Falzea, 1985).

In the opinion shared by the Author, law is of a system of legal values and a system of legal rules. Legal rules consist of two situations (factual situation or Tatbestand; effectual situation or Rechtsfolge) linked by legal causality (Rechtskausalitaet). The two situations of the same rule share a linking point: the subject. The legal subject is to be defined as the center of any legal interest and of any legal attribution (Falzea, 1997).

Legal rules, according to a certain illustrious legal scholar associate legal values to the legal facts, hence generating legal effects consisting of a factual component and an axiological component (Falzea, 1997). Even though the basics of this doctrine constitutes the pillars of the framework of the hereby proposed model, the Author believes that legal values instead of being just a component of the legal effect, characterize any unit of legal mass within any legal structure (both in any Tatbestand and in any Rechtsfolge). Some other legal doctrine (see Scalisi, 2012) has specified the essence of legal values as values of actions (instead of values of facts), in a more recent relevant contribution. Although both previously quoted theoretical constructions deserve to be taken into account, the Author believes that the truly essence of legal values is not to be simply related with facts, nor just with actions, but 
more broadly with the (logical and/or chronological) organization of legal mass within legal structures between two different subjective terminals (subject $\alpha$, or outsider, who claims his interest on an element, or object; subject $v$, or incumbent, who is the property right owner on the object in the status quo ante allocation).

Another well-established doctrine (Hartmann, 1926, pp. 269-335), whose thoughts form another important pillar in the framework of this model, has distinguished two axiological dimensions: Strength (Wertstaerke) and Height (Werthoehe). The former measures the easiness for an axiological potential to be acknowledged and perceived; the latter measures the merit of the interest shown by the value at stake. Some scholars, further deepening the study of the relationships between such two axiological dimensions, have stated a basic relation of inverse proportionality between them (see De Stefano, 1954, as summarized in Scalisi, 2012, pp. 227-260; Spadaro, 1994). Although such statement has been an important source of inspiration for the shaping of the two elementary axiological equations upon which this model is founded, the Author believes that such a simple rule of inverse proportionality does not entirely catch the much bigger complexity of the linkage between such two axiological dimensions.

\section{Basic Factors for This Model:}

The present model is based upon the previous general assertions on the main features of law (a system of values; a system of rules; facts, effects, causality, subjects, object; height and strength). The model consists of three main factors, whose combination gives rise to the its fundamental structure: mass; value; information (hence restating what already asserted in FerraraGaglioti, 2012).

Legal mass is formed by "bricks" with which any legal structure (i.e., in order of increasing complexity: position, situation, rule, principle, system) is formed; their main feature is that of being capable of assuming axiological push, once they are positioned within an organized and orderly sequence, from a subject (the outsider) to another (the incumbent).

As to the concept of legal value, the Author refers back to what already stated in the previous lines of this paragraph.

As to information, it can be either conceptual information (i.e. the ideal content associated to a unit of conceptual mass) or mere chronological information (i.e. information about what comes at the same organizational level, or before, or later, within a legal structure).

For instance, when one deals with the framing of the factual situation of the rule enshrining the right to human life, one might opine that such right derives from or the procreation or the birth of a human being. In the former option, the factual situation consists of the following units: legal subject 
(origin at the organization level $\mathrm{T}=0$ ); human persona (level $\mathrm{T}=1$ ); male (level $\mathrm{T}=2$ ); female (level $\mathrm{T}=2$ ); procreation (level $\mathrm{T}=3$ ); in the latter option, a further unit has to be added: birth (level $\mathrm{T}=4$ ). Each option implies a different axiological equilibrium: as it will be later exposed, the model does not a priori impose a certain option, but it allows to deeply analyze the different consequences of the interpretation adopted between the options at stake. In the above given example, the element "male" is a unit of mass delivering conceptual information (the idea of a male being presupposed by the fact of procreation); the consecutio among the units of mass depends upon logics $(\lambda \hat{\gamma} \gamma \circ \varsigma)$, not being reasonably possible to dispute that, e.g., the concept of "birth" (at a certain level $T_{n}$ ) supposes the concept of "procreation" (at a certain level $T_{m}=T_{n}-1$ ). The path of units of conceptual mass from the origin (Subject $\alpha$ ) to the object is called legal Position. In any legal Situation it is possible to detect more than one legal Positions; furthermore, it is possible to ascertain that once the many Legal Positions are assembled to form a Legal Situation, there might be a certain asymmetry as to the precise determination of the organizational level of each unit of conceptual mass. When it occurs, it is not possible to determine at which organizational level a certain unit of conceptual mass has to be allocated. The logical principle of non-contradiction imposes that any concept has to allocated in just one organizational level. To solve this contradiction, the only way is that of adopting a certain privileged viewpoint (the incumbent's one, or the outsider's one). Once a privilege is conventionally adopted by the policy-maker, one of the units of mass at stake, which would deliver the same conceptual content in different organizational levels, will be sort of obscured, losing its conceptual information, due to the viewpoint of the privileged observer. The unit of mass originally delivering conceptual information, which is then obscured, according to the above reasoning, is called "gap-mass": each unit of gap-mass carries only chronological information, but no more conceptual information. In any case, both conceptual mass and gap-mass imply a consecutio (hence, organization) of legal mass within a legal structure in the logical legal Time between two subjects (outsider $\alpha$ and incumbent $\beta$ ). Both conceptual mass and gap-mass assume axiological drive and energy, being weighed in the axiological dimensions of Strength and Height.

\section{Legal Organization and Legal Values in this Model:}

Legal organization of legal mass within legal structures, can then assume two different ways: logical organization as to conceptual mass

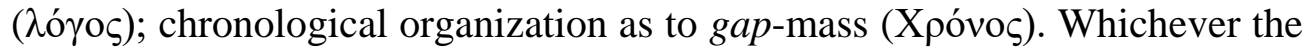
kind of legal mass, it is always associated to legal values and to legal organization. In this sense, the truly nature of legal values is of organizational 


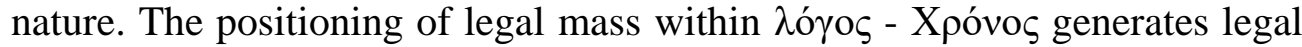
values.

Legal value, within this model, is the force of attraction exercised by legal subjects to legal mass: the quantification, identification and balance of such axiological forces turn out to be decisive in determining to which competing legal sphere the objects will be adjudicated; in this way, the conflict between (at least) two subjects opposing more legal entitlements among them, will be solved with a due process of axiology (i.e. a fairly objective and transparent balance).

Legal mass is the legal entity capable of legal value, once orderly organized. Units of mass without organization are not capable of driving axiological forces: they do not assume legal values. Hence, gi $\delta \omega \lambda$ ov (conceptual contents) is not what is essential to legal values, but instead organization.

Legal values are created once legal structures are framed in orderly organized consecutiones: the consecutio (i.e. organization) is necessary to frame each path leading a subject (the outsider) to contest the status quo ante allocation of the property right concerning a certain object (i.e. the incumbent's property right). Due to the fact the gap-mass inserts within this model a certain factor of uncertainty (because it cannot deliver conceptual information, being neutral under a conceptual point of view), it implies transaction costs within the market of legal entitlements and legal adjudications. For this fundamental reason, the initial status quo ante allocation is important and it can impact the final allocation of properties; then, this is an argument against the (full) applicability of the Coasian theorem of indifference of the status quo ante in the allocation of property rights. In effect, given the transactional costs implied by gap-mass in any legal structure, it is not possible to assume that the initial allocative pattern is indifferent to the final equilibrium, because one cannot imagine a system of perfectly efficient contracts being able to finally redistribute properties in a completely efficient manner. In fact, in the Author's opinion, the status quo ante allocation influences the final equilibrium, as well as the identification of the privileged viewpoint characterizes the policy of the system: if the privilege comes with the incumbent, the policy is of conservative orientation; vice versa, if the privilege comes with the outsider, the policy is of progressive orientation.

Considering that the axiological potential associated to the units of gap-mass within a legal structure is neutral, under a conceptual information point of view, this quota of gap-mass-related axiological potential is of discretionary nature, that is to say that its usage belongs to the sphere of discretional policy of the decision-maker. Given that in any legal structure a certain variable number of gap-mass units emerges, any legal choice and any legal decision imply a certain (variable) margin of discretionary power for the 
decision-maker. If the decision respects the boundaries of such quota, the decision is legally valid, though eventually politically disputable; however, whenever such boundaries are violated, the principle of the rule of law does require a legal remedy to challenge this invalid decision, whatever its legal vest (law, sentence, administrative order, contract, etc.).

Instead the whole axiological potential associated to conceptual mass cannot be disputed: it has to be de plano recognized by any decision-maker, as it fully delivers both chronological and logical information, that cannot be put in doubt in any legal assessment.

The whole model, hereabove summarized and restated, basically relies on two elementary and fundamental mathematical relationships, describing the trends of the axiological dimensions of Strength and Height associated to a unit of mass, depending upon its organisational allocation within the legal structure under examination.

The assumptions underlying such functions state that the nearer the mass to the Outsider, the more it gains axiological Height (as the Outsider is the center of the interest for the object); instead, the nearer the Mass to the Incumbent, the more it gains axiological Strength (as the Incumbent is actually put into the position of the status quo ante, hence the effectiveness of reality). Such two functions may be then described as follows:

$$
H_{n}=e^{-\left(T_{n}-1\right)}
$$

Legenda:

$\mathrm{H}=$ axiological Height

$\mathrm{n}=$ each $\mathrm{n}$-th unit of mass

$T_{n}=$ the organisational level of the $\mathrm{n}$-unit of mass

$\mathrm{e}=$ Neperus constant

\section{Axiological Height}

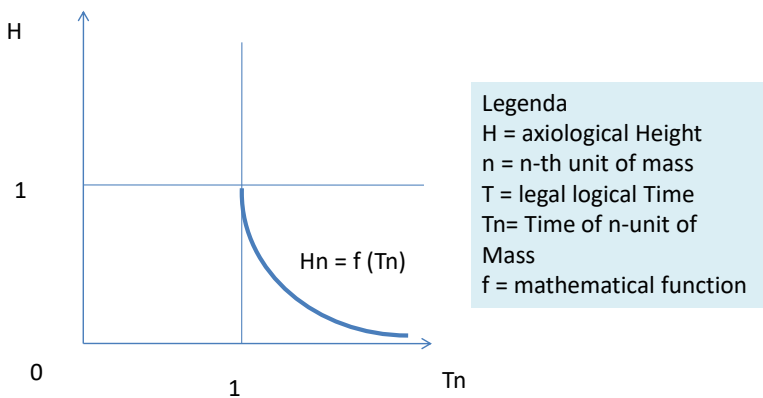


Legenda:

$$
S_{n}=e^{-\left(T_{\max }-T_{n}\right)}
$$

$\mathrm{S}=$ axiological Strength

$\mathrm{n}=\mathrm{n}$-th unit of mass

$T_{\max }=$ organisation level of the most peripheral unit of mass within the legal structure

$T_{n}=$ organisational level of the $\mathrm{n}$-th unit of Mass

$\mathrm{e}=$ Neperus constant

\section{Axiological Strength}
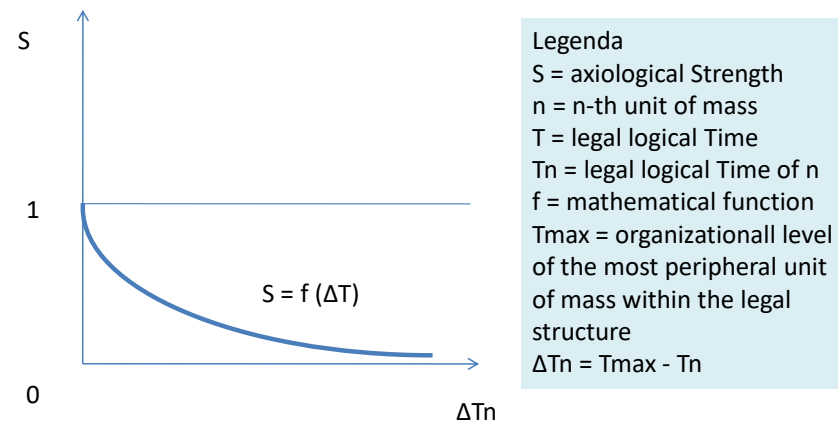

To sum up the basics of the model hereabove exposed and restated, the Author believes that the consecutio of units of mass in orderly organized sequences generates the legal dimension of Time (Xpóvos). Instead, the introduction of the two subjects, respectively at the beginning and at the end of these chronological chains of legal mass, introduces the legal dimension of

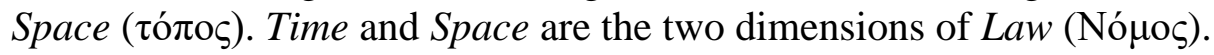

\section{Organizational Flows in this Model:}

The above model might be graphically exposed describing some flows among its basic variables. There is an organizational (logical and/or chronological) flow among the units of mass. The first unit of mass relates the organizational flow to the outsider (subject $\alpha$ ): it usually consists of capacity and/or human persona (on those legal concepts, see FALZEA, 1997). The last unit of mass of the organizational flow is the object. The relationship between the outsider and the object is human interest (which describes a substantial flow). A status quo ante property right relates the object to the incumbent (subject $\beta$ ). The relationship between the outsider and the incumbent is the 
conflict. The conflict is composed of two counteracting axiological flows: the Claim is the axiological flow relating the Outsider to the object; the Acknowledgement is the axiological flow relating back the Object to the Outsider. The relationship between Claim and Acknowledgement is the Axiological Feedback. When a Claim is coupled by the Acknowledgement, then a legal Entitlement is generated: an Entitlement can legally justify the attribution of a property right. As already stated in previous publications (see Ferrara-Gaglioti, 2012; Gaglioti, 2017), there are two main systems of Feedback within legal systems:

- $\quad$ individual feedback leaves the Acknowledgement to the individual responsibility of the Incumbent, hence the Entitlement coincides with the adjudication of the conflict within the opposed Entitlements;

- $\quad$ social feedback leaves the Acknowledgement to the responsibility of a socially construed device, which emits an axiological signal of medium intensity designed in general by the system. Consequently, in social feedback systems the entitlement is generated ex ante in comparison with the occurrence of a Conflict; the conflict regards (at least) two already generated opposed entitlements.

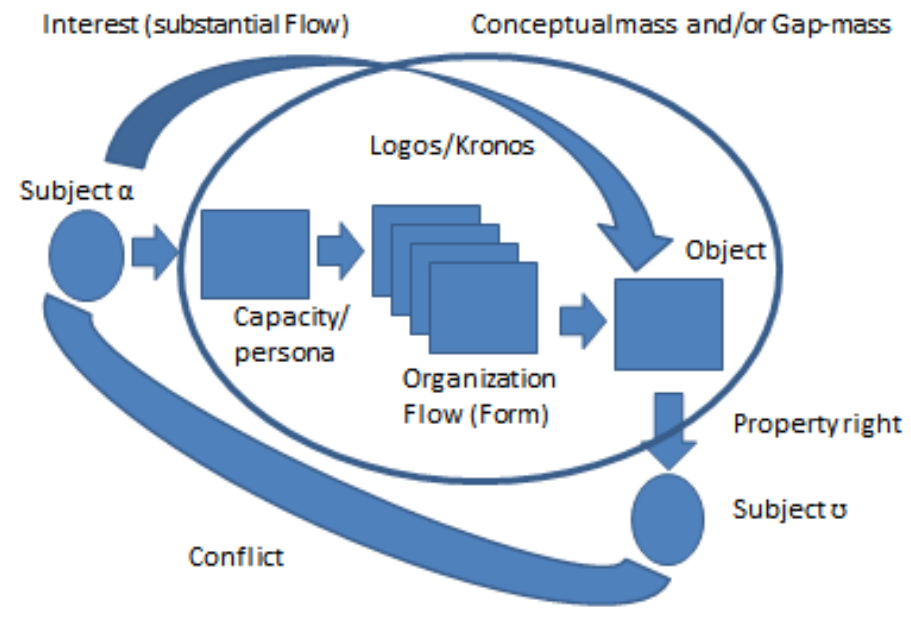

Once the basics of the proposed model have been synthetically explained, the Authors will pose some open questions, which will require additional scientific enquiries. After the axiological potential associated to some legal organisms at stake has been described and quantified, it is possible to describe the axiological potentials as axiological vectors: there will be two 
vectors for any legal rule, i.e. the vector Fact and the vector Effect. It seems, though this hypothesis has still to be better investigated, that the causality linkages between those two vectors, leads not to their vectorial Sum, but instead to their vectorial Product. The consideration of all the vectors relating the same subject to the different objects (through the vectorial products, as already stated), illustrates in a 3-D legal space the legal sphere of any legal subject. The adjudication of any object to the sphere of a certain subject might be considering as constantly disputable and in progress, because it is constantly under the pressure of competing and conflicting entitlements coming from extraneous legal spheres. It might then be possible to apply the concept of Entropy, derived from Physics, to fully analyze such axiological legal flows.

\section{Conclusion}

The Author does hope that international scientific community might consider the functioning and the framework of the above model, in order to test it, eventually criticizing and/or validating it.

The above model is allegedly viable for any legal system which is based upon reason and logics, because it only requires the possibility to organize the concepts according to their logical consecutio, notwithstanding the theoretical assumptions, nor the historical traditions, nor the specific jus positum nor the policy orientations of a particular legal system or area.

This model might lead the way to a newly conceived discipline: Law\&Mathematics. The Author believes that the mathematical analysis of law might constitute a sort of new lingua franca in legal reasoning, which might promote the mutual understanding among the different legal systems, and consequently better cooperation, to the ultimate ends of peace, progress and justice, in coherence with other attempts seeming orientated in the same way, as to the construction of a "legal idiom" to address some questions that require answers "in legal focus through an elaboration of a contemporary perspective of the right concepts" (see, e plurimis, Skenderaj, 2015).

The tools deployed via the present model might, in the author's opinion, extend to the legal area plenty of concepts and schemes already successfully used in economics and other social sciences (see, for es., Becker, 2014).

\section{References}

1. Becker P. (2014), European Scientific Journal, Special Edition, How interpreting business principles through the lens of "New Science" can help social organisations respond to global and local threats and opportunities while protecting their goals and values; a health care 
example of scientific humanism, Complexity, A, http://dx.doi.org/10.19044/esj.2014.v10n10p\%25p

2. De Stefano, R., (1954). Per un'etica sociale della cultura. Vol. 1, IT: Giuffrè.

3. Falzea, A., (1985). Introduzione alle scienze giuridiche. Milano, IT: Giuffrè.

4. Falzea, A., (1997). Ricerche di teoria generale del diritto e di dogmatica giuridica. Vol. 2: Dogmatica giuridica. Milano, IT: Giuffrè.

5. Ferrara, M. \& Gaglioti, A.R., (2012). Law\&Mathematics. Il diritto nel prisma di un modello matematico. Roma, IT: Rubbettino.

6. Ferrara, M. \& Leonardi, S., (2001). Elementi di matematica per le applicazioni economiche e finanziarie, Messina, IT: EDAS.

7. Gaglioti, A.R. (2017). Azioni positive in favore dei disabili: impatto (e limiti) dei rimedi nell'ottica di un modello matematico di analisi assiologica. Rivista Critica di Diritto Privato, 3, pp. 463-485, Napoli, IT: Jovene.

8. Gorassini, A. (2006). Il concetto di persona rispetto al concetto di soggetto, Atti del Convegno dei civilisti italiani a Capri nel 2005. Napoli, IT: Edizioni Scientifiche Italiane.

9. Hartmann, N., (1926). Ethik. Berlin-Leipzig, DE: de Gruyter.

10. Scalisi, V., (2012). Fonti, teoria, metodo: alla ricerca della regola giuridica nell'epoca della postmodernità. Milano, IT: Giuffrè.

11. Skenderaj M. (2015), Law, Rights, and Justice: the Defences of Human Rights and Freedom, European Scientific Journal, Vol. 11, N. 34, http://dx.doi.org/10.19044/esj.2015.v11n34p\%25p

12. Spadaro, A., (1994). Contributo per una teoria della Costituzione, I, Fra democrazia relativista e assolutismo etico, 1994. Milano, IT: Giuffrè. 